\title{
Design, synthesis and evaluation of molecularly targeted hypoxia-activated prodrugs
}

Liam J. O'Connor ${ }^{1,2}$, Cindy Cazares-Körner ${ }^{1,2, t}$, Jaideep Saha ${ }^{1, \dagger}$, Charles N. G. Evans ${ }^{1,2}$, Michael R. L. Stratford ${ }^{2}$, Ester M. Hammond ${ }^{2 *}$ and Stuart J. Conway ${ }^{1 *}$

${ }^{1}$ Department of Chemistry, Chemistry Research Laboratory, University of Oxford, Mansfield Road, Oxford, OX1 3TA, UK.

${ }^{2}$ CR-UK/MRC Institute for Radiation Oncology, Department of Oncology, University of Oxford, Oxford, OX3 $7 D Q, U K$.

${ }^{*}$ To whom correspondence should be addressed:

\section{Stuart J Conway}

Chemistry Research Laboratory

Department of Chemistry

University of Oxford

Mansfield Road

Oxford, OX1 3TA

stuart.conway@chem.ox.ac.uk

\section{Ester M Hammond}

CR-UK/MRC Oxford Institute for Radiation Oncology

Department of Oncology

University of Oxford

Oxford, OX3 7DQ

ester.hammond@oncology.ox.ac.uk

${ }^{\dagger}$ These authors contributed equally to this work. 


\begin{abstract}
Hypoxia, regions of insufficient oxygen supply, occur in diverse contexts across biology in both healthy and diseased organisms. The difference in the chemical environment between a hypoxic biological system and one with normal oxygen levels provides an opportunity for targeting compound delivery to hypoxic regions, using bioreductive prodrugs. Here, we detail a protocol for the efficient synthesis of (1-methyl-2-nitro- $1 \mathrm{H}$ imidazol-5-yl)methanol, which is a key intermediate that can be converted into a range of 1-methyl-2-nitro$1 \mathrm{H}$-imidazole-based precursors of bioreductive prodrugs. We outline methods for attaching the bioreductive group to a range of functionalities, and discuss the strategy for positioning of the group on the biologically active parent compound. The procedure also describes a suite of reduction assays, of increasing biological relevance, to validate the bioreductive prodrug. These assays are applied to an exemplary compound. This protocol has broad applications to the development of hypoxia-targeted compounds.
\end{abstract}

\title{
INTRODUCTION
}

\section{Background}

Regions of low oxygen (hypoxia) occur in a diverse range of biological contexts, including disease states, bacterial infections and some healthy organs ${ }^{1,2}$. Notably, during tumor development, oxygen supply quickly becomes a growth-limiting factor, due the high number of metabolically active tumor cells. In response to the problem of inadequate oxygen supply, the process of angiogenesis is initiated to create a tumor vasculature. However, this vasculature has many aberrant features, and although it manages to sustain the tumor, it also results in regions of hypoxia, in which only the most aggressive fraction of the tumor cells can survive ${ }^{3}$. These hypoxic regions occur at distances greater than $100 \mu \mathrm{m}$ from a functional vessel, and can be both chronic and acute ${ }^{4}$. The oxygen concentration within a tumor is, therefore, extremely heterogeneous and fluctuates substantially ${ }^{5,6}$. Hypoxic cells are resistant to radiotherapy as the DNA damage induced by radiation, which is required for cell killing, occurs in an oxygen dependent manner ${ }^{7}$. Therefore, hypoxic cells comprise the most aggressive tumor fraction, and are the most important to treat, to improve patient prognosis ${ }^{8}$. Bioreductive prodrugs are biologically inactive molecules, which are converted to an active drug by enzymatic reduction ${ }^{3}$. These drugs harness the substantial differences in chemical environment between hypoxia and normoxia to target drug compounds to these therapeutically challenging tumor regions. This technology is also applicable to targeting compounds to regions of hypoxia in a wide range of other biological settings.

\section{Development of the protocol}

We have developed a protocol in which a bioreductive group precursor is synthesized and then coupled to a biologically active molecule so as to abrogate, or substantially reduce, the primary biological activity of the compound. As part of the protocol we have established a sequence of assays to confirm that the bioreductive group is reduced, that the molecule subsequently fragments, and that the desired active inhibitor is released.

To demonstrate the principle of the concept described above, we attached the bioreductive 4-nitrobenzyl group to a known Chk1 and Aurora A kinase inhibitor, with the aim of targeting this therapeutically relevant compound to areas of hypoxia ${ }^{9}$. We chose compound 6 (Figure 1) as the Chk1 inhibitor to study as it had a clear structure-activity relationship (SAR) profile that indicated alkylation of the primary hydroxyl group would result in a substantial loss of activity, and furthermore, because such a modification would be synthetically 
simple. Compound 1 was synthesized and subjected to the reduction assays to determine whether fragmentation occurs, and if the intact, active kinase inhibitor was consequently released. First, exposure to zinc and ammonium chloride in DMF resulted in the formation of the nitroso- (4) and amine-derived (5) reduction products. Stirring these products in phosphate buffer at $\mathrm{pH} 7.4$ resulted in fragmentation to give the active kinase inhibitor (6). Compound 1 was then treated with bactosomal human NADPH-CYP reductases in potassium phosphate buffer under hypoxic conditions. Again, reduction and fragmentation to release the active kinase inhibitor (6) was observed, whereas under normoxic conditions the prodrug (1) was stable. Having shown that Compound 1 acted as a bioreductive prodrug, we demonstrated that treatment of RKO, A549, H1299 or H1975 cells resulted in increased DNA damage, consistent with the release of a Chk1 inhibitor, in an oxygen-dependent manner'.

The work described above utilized the 4-nitrobenzyl bioreductive group. However, many hypoxia-activated compounds employ the 1-methyl-2-nitroimidazole group as the bioreductive functionality (vide infra). Despite this common usage, synthesis of 1-methyl-2-nitroimidazoles following literature procedures has proved challenging. Therefore, to address this problem we have recently reported a high-yielding, rapid and reliable route to a key intermediate in the synthesis of 1-methyl-2-nitroimidazole-based bioreductive prodrugs ${ }^{10}$. The intermediate can be transformed into 1-methyl-2-nitroimidazole derivatives 14-18 (Figure 2) that contain useful synthetic handles for attachment of the bioreductive group to a range of functional groups. Our synthesis builds on the work published by Cavalleri et al. ${ }^{11}$ and a patent disclosed by Matteucci et al. ${ }^{12}$.

\section{Applications of the method}

To date, we have applied our methodology to demonstrate oxygen-dependent release of a biologically active compound in tumor cells lines. The next phase of our work will be to demonstrate targeting of the compounds to the hypoxic fraction of tumors. However, in addition to solid tumors, the occurrence of hypoxia is more widespread throughout biology. For example, areas of the kidney have a much lower oxygen tension than most other parts of the body, and biofilms can also become substantially hypoxic. Consequently, this protocol could potentially be adapted to enable the selective delivery of compounds in these settings.

\section{Comparison with other methods}

Most of the previous work in the bioreductive field has focused on the use of bioreductive groups that selectively activate alkylating agents, or similar compounds, which cause direct DNA damage and/or other non-specific cytotoxicity ${ }^{3}$. Examples of such compounds include E09, RH1 and AQ4N the activation of which is based on a quinone moiety; PR-104 and NLCQ-1, which contain nitroaromatic groups; and SN30000, TPZ, CEN-209 that contain a nitroxide moiety. A number of these agents have been tested clinically, although none are in widespread use. TH-302 is the most advanced clinically and is currently in Phase II clinical trials for a variety of cancers (ClinicalTrials.gov Identifiers: NCT02093962; NCT01403610; NCT02402062; NCT00742963). It has also recently entered Phase III trials, in combination with other therapeutics, for the treatment of metastatic pancreatic cancer and metastatic soft tissue sarcoma (ClinicalTrials.gov Identifiers: NCT01746979; NCT01440088)

The approach taken in our work is distinct from that described above, as the bioreductive component is appended to the active molecule and functions as the removable component of the prodrug. Therefore, bioreduction only affects the bioreductive protecting group component of the prodrug, leading to 
fragmentation and release of the desired active drug component. Despite not being that widely used to date, there are some examples of the synthesis of biologically active compounds protected by bioreductive groups. An early example of this approach was a prodrug of a poly(ADP-ribose)polymerase (PARP) inhibitor that was protected with a 1-methyl-2-nitroimidazole or a nitrofuran group reported by Parveen and co-workers ${ }^{13}$. In this case, only the chemical reduction of the prodrug was reported. No data on the compound's propensity for bioreduction, or the activity of the protected compound was included. Damen et al. developed a range of paclitaxel-based bioreductive prodrugs with a range of protecting groups attached to the taxol side chain. In most cases these compounds underwent chemical reduction, and a number of the compounds demonstrated reduced cytotoxicity under normoxic conditions. However, bioreduction of the compounds under hypoxic conditions was not evaluated ${ }^{14}$. A less common 4,7-dioxindole-3-methyl-based prodrug was employed by Ferrer et al. to release prednisolone with the aim of targeting hypoxic regions in rheumatoid arthritis. Again, reduction was chemically demonstrated using $\mathrm{SnCl}_{2}$, but no bioreduction was reported $^{15}$. Subsequently, 20(S)-camptothecin (a DNA topoisomerase I inhibitor) ${ }^{16}$, doxorubicin ${ }^{17}$, 6thioguanine ${ }^{18}$, lysyl oxidase inhibitors ${ }^{19}, O^{6}$-benzylguanine $\left(O^{6}-B G\right.$, an inhibitor for $O^{6}$-alkylguanine-DNAalkyltransferase $)^{20}$ and IC86621 (an inhibitor of DNA-dependent protein kinase) ${ }^{21}$, have been converted to prodrugs using nitroaryl protecting groups. Fluorescent compounds have been released from a nitroquinoline group $^{22}$, or a 4-nitrobenzyl group ${ }^{23}$, and inhibitors of vascular endothelial growth factor (VEGF)-induced angiogenesis have been released from 4-nitrobenzyl- or quinone-based prodrugs ${ }^{24}$. An interesting branch of this field is self-inactivating bioreductive groups that quench the inherent electrophilicity of the bioreduction product $^{25}$. In our work, we released a Chk1 and Aurora A kinase inhibitor from a 4-nitrobenzyl-based prodrug and demonstrated an oxygen-dependent effect of the released compound in four cancer cell lines (RKO, A549, $\mathrm{H} 1299$ and $\mathrm{H} 1975)^{9}$.

\section{Experimental design}

Choice of bioreductive protecting group. Five distinct chemical moieties, nitro groups, quinones, aromatic $\mathrm{N}$-oxides, aliphatic $\mathrm{N}$-oxides, and transition metals, have been identified as being sensitive to bioreduction ${ }^{3}$. The $\mathrm{N}$-oxides have been used as bioreductive groups only when the functionality is embedded within the core structure of a molecule. Nitroaryl-based compounds have been used both as bioreductive components embedded in molecules and as groups to trigger fragmentation. For example, the nitrobenzyl moiety is employed in the structure of PR-104A, whereas in the case of TH-302, the DNA crosslinking component is released by bioreduction of a nitroimidazole group. Given their widespread use, the nitroaryl-based compounds are amongst the most amenable for use in the development of a bioreductive prodrug. In addition to the 4-nitrobenzyl and 1-methyl-2-nitroimidazole groups, nitrofuran- and nitrothiophene-based groups have also been employed as the basis of bioreductive compounds (vide supra). Of these groups, the 4-nitrobenzyl group and the 1-methyl-2-nitroimidazole group have been most extensively used.

In principle, the most important consideration when choosing which bioreductive group to use is its propensity to undergo bioreduction, and the oxygen concentration at which this process occurs. However, as oxygen-dependent bioreduction in mammals is thought to occur predominantly via a one-electron mechanism, the propensity of a particular group to undergo bioreduction does not correlate directly with a compound's electrochemical reduction potential. In addition, the instability of the $\mathrm{ArNO}_{2}-$ radical in water makes measuring these values difficult. The reduction potentials $E\left(\mathrm{ArNO}_{2} / \mathrm{ArNO}_{2}{ }^{-}\right)$versus the normal hydrogen electrode (NHE) in water at $\mathrm{pH} 7$ for commonly used nitroaryl bioreductive groups have been 
estimated and are shown in Figure $3^{26}$; a smaller negative value indicates that the group undergoes more facile reduction. As can be seen, the 1-methyl-2-nitroimidazole group (9) and the nitrothiophene-based group (8) have the same reduction potential, whereas the 4-nitrobenzyl group (10) has a more negative reduction potential, indicating that it undergoes less facile reduction. These observations can potentially be used to tune the sensitivity of the prodrug to the particular hypoxic environment to which it is to be targeted. Although values determined from the NHE are suitable guidelines, the reduction rate of the compound is also dependent on a number of other factors including the local $\mathrm{pH}^{26}$. In addition, the propensity of the drug component to be a good leaving group plays a role in the rate of its release. It is therefore possible, that under certain circumstances reduction of the protecting group might not lead to fragmentation of the prodrug.

The reagents required to attach the 4-nitrobenzyl, nitrofuran- and nitrothiophene-based groups to biologically active compounds are readily available from commercial sources. The precursors for attaching the 1-methyl-2-nitroimidazole group are less readily available, and hence we have developed an optimized protocol for synthesizing a range of derivatives with useful synthetic handles for attachment to biologically active compounds (Figure 2). Of the various conditions previously reported for this transformation, we found the optimal method to be treatment of sarcosine ethyl ester with ethyl formate and sodium hydride in a formylation step ${ }^{10}$. Removal of the unwanted $\mathrm{N}$-formyl under acidic conditions and then treatment with cyanamide in acidified ethanol afforded aminoimidazole 13. Diazotisation with sodium nitrite afforded the nitroimidazole 14, which can be viewed as the first useful product of this synthesis when developing bioreductive prodrugs. The ester can be hydrolyzed to the acid 17, or reduced directly to the alcohol 15 . Alcohol 15 was transformed to the chloride 16 by treatment with thionyl chloride and pyridine; procedures to give the corresponding bromide were typically lower yielding. Oxidation of 15 using $\mathrm{MnO}_{2}$ gave the aldehyde $18^{10}$.

The synthetic availability of the ester 14 , alcohol 15 , chloride 16 , and acid 17 derivatives affords some flexibility to the process of attaching the bioreductive group to the biologically active entity. Some useful methods for coupling the two components are shown in Figure 4. The hydroxyl group can be coupled directly to an acid chloride, or coupled to a carboxylic acid using standard ester coupling conditions. The hydroxyl group can also be converted into a good leaving group, enabling a hydroxyl group in the biologically active compound to act as a nucleophile to achieve alkylation. The carboxylic acid can be coupled to a hydroxyl group using standard coupling conditions or the ester could be directly coupled. Oxidation of the hydroxyl group to give the aldehyde allows attachment of the bioreductive group to an amine in the biologically active compound. However, consideration must be given to the generally poor leaving group ability of amines. An alternative option is coupling of the amine with a chloroformate, to give the carbamate. Fragmentation of amines via a carbamate intermediate might improve the fragmentation of the prodrug.

Position of protecting group attachment. For the bioreductive prodrug to be effective, the unreduced, protected form of the compound must be inactive at its primary cellular target, or at least display a significantly reduced activity to that of the compound released upon fragmentation. To achieve the required difference in activity, the bioreductive group must be attached to a functional group that is important for the biological activity of the released compound. In the case of $\mathrm{CH}-01$, the kinase inhibitor 6 was selected to form the basis of the molecule, as a very clear SAR had been established in the initial publication, indicating that modification of the hydroxyl group resulted in a dramatic loss of activity (Figure 5$)^{27}$. Substitution of the 
hydroxyl is thought to reduce activity by disrupting an intramolecular hydrogen bond, but also because the 4-nitrobenzyl group is too large to reside in the ATP-binding pocket of Chk1, as based on X-ray crystal structure analysis.

Subsequent work focused on another Chk1 inhibitor (19), which afforded greater choice in positions to attach the bioreductive group than that of Compound 6. Based on analysis of an X-ray crystal structure of 19 bound to Chk1, it was decided to attach the bioreductive group to the 1-position of the $1 H$-pyrazolo[3,4-b]pyridine ring, as this nitrogen atom donated a key hydrogen bond to the kinase hinge region, an interaction that is essential for compound binding (Figure 5). Using a ${ }^{32}$ P-ATP filter-binding assay, it was observed that substitution with a bioreductive group at the hydroxyl position of 6 , and at the 1-position of the pyridine ring of 19 led to a large reduction in Chk1 affinity, compared to the unsubstituted analogues.

In general, once the prodrug has been synthesized comparison of the biological activity of the parent compound in the same assay, at the same time, is essential before the work progresses. In addition, it is useful to assess the general cytotoxicity of the prodrug at this stage to ensure that the compound is suitable for use in cells.

Assessment of the reduction and bioreduction of a prodrug. To demonstrate the application of our protocol, the assays described have been employed to assess the reduction behavior of compound $\mathbf{1}$, as a representative bioreductive prodrug. Users of this protocol may apply the assays described directly to any other bioreductive prodrug compound, making necessary changes where applicable to molecular weight and concentration calculations.

To determine if the prodrug fragments as expected to give the desired product, we have developed a sequence of reduction and bioreduction assays that assess the behavior of a hypoxia-activated prodrug. In the first instance the prodrug, is treated with $\mathrm{Zn}$ powder and $\mathrm{NH}_{4} \mathrm{Cl}$ in $\mathrm{DMF}$ for a given time (typically between 0.5 and $24 \mathrm{~h}$ ) followed by stirring in potassium phosphate buffer at $\mathrm{pH} 7.4$ for $24 \mathrm{~h}$ (see protocol steps 2 | and 3|). The fragmentation of the prodrug is analyzed using HPLC. As most nitroaryl groups are reduced under these conditions, this experiment determines whether the prodrug will fragment upon reduction. In addition, as the HPLC retention time of the desired active compound will be predetermined, the experiment also confirms that the expected fragmentation product is obtained. This aspect of the protocol is only suitable when the prodrug does not contain other functionalities that are reduced under the conditions described (e.g. aryl halides).

The second experiment is to assess the propensity of the prodrug to undergo bioreduction when treated with bactosomal human NADPH-CYP reductases ${ }^{9}$. Compound $\mathbf{1}$ is again used as a representative compound for this assay (see protocol step 4|). As there are many mechanisms by which a nitroaryl-based prodrug can be reduced in vivo, and the pathways will likely vary between cell lines and types, it is not feasible to definitively assess all possible modes of enzymatic reduction in vitro. However, NADPH-CYP reductases are known to reduce nitroaryl groups in vivo in an oxygen-dependent manner, and hence provides a useful model system to predict the likelihood of the prodrug undergoing bioreduction in vivo. LCMS analysis of the reductase reaction mixture at given time points $(0.5-48 \mathrm{~h})$ enables confirmation of the reduction. In addition, it is sometimes possible to identify intermediates in the reduction pathway, including the hydroxylamine, nitroso and amine derivatives, which are produced before fragmentation to give the final product. An absence of 
reduction in a normoxia control experiment will provide evidence for the reduction being oxygen dependent and enzyme-mediated.

The final analysis of the prodrug assesses its bioreduction in a representative cell line. Here we describe the procedure using cultured RKO (colorectal) cells, however, we have found that HCT116, OE21, A549, HepG2 and $\mathrm{H} 1299$ cells are also suitable for these experiments (see protocol step $5 \mid$ ). The chosen cells are treated with the compound under either normoxic or hypoxic conditions, the cells lysed, and the presence of the parent compound, and its metabolites, analyzed by HPLC and/or LCMS. For initial testing of we have found using almost anoxic conditions $\left(<0.1 \% \mathrm{O}_{2}\right)$ to be ideal, but this approach can then be extended to studies at milder levels of hypoxia (e.g. 0.5-2 \% $\mathrm{O}_{2}$ ).

\section{Limitations}

A number of potential limitations exist for this protocol that should be highlighted: 1 . It might not be possible to attach the bioreductive group to the bioactive compound in a manner that sufficiently disrupts the biological activity of the parent molecule. 2. The leaving group ability ( $\mathrm{pKa}$ ) of the atom to which the bioreductive group is attached plays an important role in the overall fragmentation process. Attachment of the bioreductive group to a poor leaving group will result in the fragmentation process stalling once the nitro group has been reduced. This limitation can be potentially overcome by attaching the bioreductive group to the parent molecule via a linker (e.g. a carbonate group) that itself is a good leaving group and will enhance the overall fragmentation process. 3. The zinc reduction assay is not compatible with compounds that contain functional groups that are unstable under the reaction conditions. Under these circumstances, alternative chemical conditions for the reduction of the nitroaryl group can be employed. ${ }^{28}$

\section{Figure Legends}

Figure 1| Attachment of the 4-nitrobenzyl group to the terminal hydroxyl group of the Chk1 inhibitor 6 affords the inactive compound 1. Under hypoxic conditions, the nitro group is reduced to form an electron-donating substituent, which induces fragmentation, and ejects the active Chk1 inhibitor $6^{9}$. Reprinted with permission from Cazares-Korner, $\mathrm{C}$. et al. $\mathrm{CH}-01$ is a Hypoxia-Activated Prodrug That Sensitizes Cells to Hypoxia/Reoxygenation Through Inhibition of Chk1 and Aurora A. ACS Chem. Biol. 8, 1451-1459 (2013). Copyright 2015 American Chemical Society

Figure 2| Synthetic scheme for the preparation of the ester- (14), hydroxyl- (15) chloromethyl- (16), carboxylic acid- (17) and aldehyde-based (18) nitroimidazole derivatives ${ }^{10}$.

Figure 3| Estimated values of reduction potentials $E\left(\mathrm{ArNO}_{2} / \mathrm{ArNO}_{2}^{-}\right)$vs normal hydrogen electrode (NHE) in water at $\mathrm{pH} 7$ for commonly used nitroaryl bioreductive systems $(7-10)^{26} . \mathrm{R}=$ alkyl or hydroxyalkyl.

Figure 4 | Possible methods of attaching the bioreductive group $\left(\mathrm{O}_{2} \mathrm{~N}-\mathrm{Ar}\right)$ to the biologically active compound (R). 
Figure 5| Analysis of possible positions to which a bioreductive group may be attached on compounds 6 and 19. 


\section{MATERIALS}

\section{REAGENTS}

! CAUTION Most of the reagents and solvents used in the protocol should be handled with care and require the use of protective goggles, gloves and lab coats. All manipulations must be performed in well-ventilated laboratory fume hoods.

\section{Chemical synthesis}

Tetrahydrofuran (THF, Sigma-Aldrich, cat. no.34865)

Methanol (MeOH, Sigma-Aldrich, cat. no.34860)

Dichloromethane $\left(\mathrm{CH}_{2} \mathrm{Cl}_{2}\right.$, Sigma-Aldrich, cat. no.34856)

Acetic acid (AcOH, Sigma-Aldrich, cat. no.320099)

Acetone (Sigma-Aldrich, cat. no.34850)

Ethanol (EtOH, Sigma-Aldrich, cat. no.32221)

Hexane (Sigma-Aldrich, cat. no.34859)

Ethyl acetate (EtOAc, Sigma-Aldrich, cat. no.34858)

Petroleum ether (PE, 40-60 ${ }^{\circ} \mathrm{C}$ boiling point, Sigma-Aldrich, cat. no.34491)

N,N-Dimethylformamide (DMF; Sigma-Aldrich, cat. no. D4551)

Pyridine, Anhydrous (Sigma-Aldrich, cat. no. 270970)

Acetonitrile $\left(\mathrm{CH}_{3} \mathrm{CN}\right.$; Sigma-Aldrich, cat. no. 34851)

Sarcosine ethyl ester hydrochloride (Sigma-Aldrich, cat. no. 255084)

Ethyl formate (Sigma-Aldrich, cat. no. 112682)

Sodium hydride (NaH, 60\% dispersion in mineral oil, Sigma-Aldrich, cat. no. 452912)

! CAUTION NaH is pyrophoric and can cause severe burns on skin contact. It reacts violently with alcohols and water and liberates hydrogen gas. Excess $\mathrm{NaH}$ can be quenched with 2-propanol.

Cyanamide (Sigma-Aldrich, cat. no. 187364)

Sodium nitrite $\left(\mathrm{NaNO}_{2}\right.$, Sigma-Aldrich, cat. no. 237213)

Sodium borohydride $\left(\mathrm{NaBH}_{4}\right.$, Fisher Scientific, cat. no 10409190)

Trifluoroacetic acid (TFA, Sigma-Aldrich, cat. no. 302031)

Trichloroacetic acid (TCA, Sigma-Aldrich, cat. no. T6399)

Formic acid (FA, Sigma-Aldrich, cat. no. 56302)

Concentrated hydrochloric acid (conc. HCl, Fisher Scientific, cat. no. 10251183)

! CAUTION conc. $\mathrm{HCl}$ is corrosive and can cause severe burns on skin contact.

Sodium sulfite $\left(\mathrm{Na}_{2} \mathrm{SO}_{3}\right.$, Sigma-Aldrich, cat no. 239231)

Magnesium sulfate $\left(\mathrm{MgSO}_{4}\right.$, Fisher Scientific, cat. no. 10224680)

Potassium carbonate $\left(\mathrm{K}_{2} \mathrm{CO}_{3}\right.$, Fisher Scientific, cat no. 10121440)

Sodium hydrogen carbonate $\left(\mathrm{NaHCO}_{3}\right.$ Fisher Scientific, cat no. 10020510)

Sodium hydroxide (NaOH, Fisher Scientific, cat no. 10306200)

! CAUTION NaOH is corrosive and can cause severe burns on skin contact.

Sodium chloride ( $\mathrm{NaCl}$, Fisher Scientific, cat no. 10112640)

Thionyl chloride $\left(\mathrm{SOCl}_{2}\right.$; Sigma-Aldrich, cat. no. 88952)

! CAUTION SOCl 2 is corrosive and can cause severe burns on skin contact.

Manganese (IV) dioxide $\left(\mathrm{MnO}_{2}\right.$, Sigma-Aldrich, cat. no. 243442) 
Argon gas (BOC, cat. no. 2936780)

\section{Chemical Reduction (See protocol steps 2| and 3|)}

Zinc dust (Sigma-Aldrich, cat. no. 209988)

Ammonium chloride (Fisher Scientific, cat. no. 10060030)

$\mathrm{N}, \mathrm{N}$-Dimethylformamide (DMF; Sigma-Aldrich, cat. no. D4551)

Dimethyl sulfoxide (DMSO, Sigma-Aldrich cat. no. D8418)

$0.5 \mathrm{M} \mathrm{pH} 7.4 \mathrm{~K}_{2} \mathrm{HPO} 4$ buffer (BD Gentest, cat. no. 451201)

\section{Bioreductive assays (See protocol steps $4 \mid$ and $5 \mid$ )}

Dimethyl sulfoxide (DMSO, Sigma-Aldrich cat. no. D8418)

Solution A (Comprises $\mathrm{MgCl}_{2}$, NADP+ and Glucose-6-Phosphate, Corning, cat. no. 451220)

Solution B (Comprises Glucose-6-phosphate dehydrogenase, Corning, cat. no. 451200)

$0.5 \mathrm{M} \mathrm{pH} 7.4 \mathrm{~K}_{2} \mathrm{HPO} 4$ buffer (BD Gentest, cat. no. 451201)

Bactosomal human NADPH-CYP reductases (Cypex, cat. no. CYP004)

Acetonitrile $\left(\mathrm{CH}_{3} \mathrm{CN}\right.$; Sigma-Aldrich, cat. no. 34851)

RKO Cells (Colorectal, ATCC, cat no. ATCC ${ }^{\circledR}$ CRL-2577 ${ }^{\text {TM }}$ )

! CAUTION Regularly check that the cell lines used in your research match their recognized cell line identity criteria and are not infected with mycoplasma.

Dulbecco's modified eagle medium (DMEM, Sigma-Aldrich, cat. no. D6046)

Fetal bovine serum (FBS, Autogen Bioscience; cat. no. S0615)

Penicillin-streptomycin (Life Technologies, cat. no. 15140-122)

$1 \times$ Phosphate buffered saline (PBS, Fisher Scientific, cat. no. 10173433)

\section{EQUIPMENT}

\section{General}

Refrigerators $\left(-80,-20\right.$ and $\left.4{ }^{\circ} \mathrm{C}\right)$

Access to analytical facilities (HPLC, LCMS, NMR and HRMS)

\section{Chemistry}

Analytical weighing balance

Spatulas

Round-bottom flasks

Teflon-coated magnetic stir bars

Rubber septa

Disposable syringes and needles

Balloons (for creating inert atmospheres in flasks)

Hotplate stirrers

Oil bath (Equipped with silicone oil)

Silica thin-layer chromatography (TLC) plates (Silica gel 60 F254, Merck)

Capillary spotters

TLC developing chamber 
Methods for visualizing TLC (UV-lamp or dips $\left[\mathrm{KMnO}_{4}\right.$, 4-anisaldehyde, phosphomolybdic acid stains])

Universal indicator paper

Rotary evaporator with water bath

Sintered funnel

Conical flasks

Separating funnels $(50 \mathrm{~mL}, 100 \mathrm{~mL}$ and $250 \mathrm{~mL})$

Glass columns for column chromatography (Diameters: $30 \mathrm{~mm}, 20 \mathrm{~mm}, 10 \mathrm{~mm}$ )

Celite $\rightarrow 545$ (Sigma-Aldrich, cat. no. 419931)

Silica gel for column chromatography (Geduran Si 60, Merck-Millipore, cat no. 111567)

Plastic funnel

Test tubes

Measuring cylinders

Vacuum gas manifold (Schlenk line)

Heavy duty rubber tubing (for manifold)

Vacuum pump

Desiccator (for drying samples under high vacuum)

Solvent purifier (mBraun SPS-800)

Distillation apparatus

Filter tips (Supelco, Iso-Disc ${ }^{\text {TM }}$ Filters, PTFE-4-4, Size x Porosity: 4 mm x $0.45 \mu \mathrm{m}$ )

\section{Biology}

Bactron- II Anaerobic Chamber (Shell Labs) or similar hypoxia chamber

Whitley H35 Hypoxystation (Don Whitley) or similar controlled oxygen chamber

Aerobic Incubator $\left(37^{\circ} \mathrm{C}\right)$

Standard incubator for mammalian tissue culture, maintained at $37{ }^{\circ} \mathrm{C}, 21 \% \mathrm{O}_{2}$ and $5 \% \mathrm{CO}_{2}$

Sterile distilled water

HPLC vials

Screw cap vials

Cell culture hood

Bench top light microscope

Cell culture flasks

Falcon conical centrifuge tubes

Pipetboy pipette controller

Pipettes

Neubauer chamber (Basic Hemacytometer)

Microfuge tubes

Centrifuge

Cell scrapers

$6 \mathrm{~cm}$ Glass Petri dishes 


\section{EQUIPMENT SETUP}

Analytical HPLC to identify reaction prodructs. In this protocol, HPLC analysis was carried out on a PerkinElmer Flexar system with a Binary LC Pump and UV/VIS LC Detector and a Dionex Acclaim® 120 column $(5 \mu \mathrm{m}, 150 \times 4.6 \mathrm{~mm})$, although other similar systems may be used. Employ a 10-minute gradient as described in Table 1, where solvent $\mathrm{A}$ is $95 \% \mathrm{H}_{2} \mathrm{O}-5 \%$ ( $\left.\mathrm{vol} / \mathrm{vol}\right) \mathrm{MeCN}+0.1 \%$ (vol/vol) TFA and solvent B is $5 \%(\mathrm{vol} / \mathrm{vol}) \mathrm{H}_{2} \mathrm{O}-95 \%$ ( $\left.\mathrm{vol} / \mathrm{vol}\right) \mathrm{MeCN}+0.1 \%$ ( $\left.\mathrm{vol} / \mathrm{vol}\right)$ TFA. The flow rate is $1 \mathrm{~mL} / \mathrm{min}$ and data are collected at $254 \mathrm{~nm}$ or $360 \mathrm{~nm}$ unless otherwise stated.

TABLE 1. HPLC analysis method

\begin{tabular}{|c|c|c|c|}
\hline $\begin{array}{c}\text { Step length } \\
(\mathrm{min})\end{array}$ & $\begin{array}{c}\text { Elapsed time } \\
(\mathrm{min})\end{array}$ & $\% \mathrm{~A}$ & $\% \mathrm{~B}$ \\
\hline 2 & 2 & 60 & 40 \\
\hline 10 & 12 & 0 & 100 \\
\hline 2 & 14 & 0 & 100 \\
\hline 1 & 15 & 60 & 40 \\
\hline 5 & 20 & 60 & 40 \\
\hline
\end{tabular}

Analytical HPLC to determine compound purity, Carry out HPLC analysis on a Waters 2695 system using a Hichrom RPB column $\left(100 \times 3.2 \mathrm{~mm}, 35^{\circ} \mathrm{C}\right)$ or a Gemini NX column $\left(150 \times 3.0 \mathrm{~mm}, 35^{\circ} \mathrm{C}\right)$. Other similar HPLC systems may be used. Separation is achieved at a flow rate of $0.5 \mathrm{~mL} / \mathrm{min}$ with a gradient of $\mathrm{MeCN}$ in $10 \mathrm{mM}$ aqueous formic acid over 6 min when using the RPB column. For compound detection, use a photodiode array spectrophotometer (Waters 2996) and a mass spectrometer (Waters Micromass ZQ mass spectrometer). $10 \mu \mathrm{L}$ injections are made. Inject samples dissolved in in $\mathrm{DMSO}, \mathrm{MeCN}, \mathrm{H}_{2} \mathrm{O}$, or a mixture thereof.

\section{PROCEDURE}

\section{1| Synthesis of nitroimidazole derivatives:}

(A) Synthesis of compound 13 TIMING 8-10 h

(i) Add $2.00 \mathrm{~g}$ of sarcosine ethyl ester hydrochloride, $11(0.013 \mathrm{~mol})$ to a $500 \mathrm{~mL}$ round bottom flask equipped with a Teflon-coated magnetic stir bar.

CRITICAL STEP If the commercial sarcosine hydrochloride is not in a powder form, we recommend grinding it in a mortar and pestle before addition.

(ii) Add $45 \mathrm{~mL}$ of ethyl formate and $45 \mathrm{~mL}$ of THF to the reaction flask to form a suspension. Stir the suspension vigorously. Add $5 \mathrm{~g}$ of $\mathrm{NaH}$ (60\% dispersion in mineral oil, $0.13 \mathrm{~mol}$ ) slowly at ambient temperature (typically $18-21^{\circ} \mathrm{C}$ in our laboratory) under an atmosphere of nitrogen or argon, and stir for $3 \mathrm{~h}$. A pale yellow suspension should form. 
! CAUTION NaH is pyrophoric and can cause severe burns on skin contact. It reacts violently with alcohols and water and liberates hydrogen gas. This step should be performed carefully with portion-wise addition and in a well-ventilated fume hood. For reaction scales over $5 \mathrm{~g}$, cool the reaction mixture to $0{ }^{\circ} \mathrm{C}$ and vent the flask with a needle outlet. Necessary precautions against any fire and explosion should be taken.

(iii) Concentrate the reaction mixture on a rotary evaporator at $40^{\circ} \mathrm{C}$ for approximately $20 \mathrm{~min}$, or until dry. Triturate the resulting yellow solid with $75 \mathrm{~mL}$ of hexane to remove the mineral oil, and decant the hexane off from the solid. Repeat the trituration with $75 \mathrm{~mL}$ hexane.

(iv) Dry the pale yellow solid under reduced pressure on a rotary evaporator at $40^{\circ} \mathrm{C}$ for approximately 10 min.

(vi) Re-equip the flask containing the yellow solid with a Teflon-coated magnetic stir bar.

(vii) Add $40 \mathrm{~mL}$ absolute $\mathrm{EtOH}$, and $8 \mathrm{~mL}$ concentrated aqueous $\mathrm{HCl}$ solution. Reflux reaction mixture under reflux for $2 \mathrm{~h}$. A colorless solid should form, and the supernatant reaction solution should be pale yellow.

! CAUTION Add conc. $\mathrm{HCl}$ slowly, in an open flask in a well-ventilated area, as liberation of $\mathrm{HCl}$ gas can occur.

(viii) Remove the colorless solid by filtration while hot, through a sintered funnel into a clean $500 \mathrm{~mL}$ round bottom flask. Wash the colorless solid in the sintered funnel with $30 \mathrm{~mL}$ of boiling absolute $\mathrm{EtOH}$, twice. Combine the filtrates, and remove the $\mathrm{EtOH}$ under reduced pressure on a rotary evaporator at $40{ }^{\circ} \mathrm{C}$ for approximately $30 \mathrm{~min}$.

(ix) Dilute the remaining aqueous solution from step (viii) with $70 \mathrm{~mL}$ of absolute EtOH and $30 \mathrm{~mL}$ of distilled $\mathrm{H}_{2} \mathrm{O}$. Adjust the $\mathrm{pH}$ of the solution to 3 , as determined by universal indicator paper, using a $2 \mathrm{M}$ aqueous solution of $\mathrm{NaOH}$.

(x) Add $1.09 \mathrm{~g}$ of cyanamide $(0.026 \mathrm{~mol})$ to the solution and heat under reflux for $1.5 \mathrm{~h}$. Allow the reaction solution to cool to ambient temperature, and concentrate the reaction solution to approximately $1 / 8$ of the original volume under reduced pressure on a rotary evaporator at $50{ }^{\circ} \mathrm{C}$ for approximately $20 \mathrm{~min}$.

(xi) Adjust the $\mathrm{pH}$ of the solution to 8-9, using solid $\mathrm{K}_{2} \mathrm{CO}_{3}$, as determined by universal indicator paper.

CRITICAL STEP Upon approaching $\mathrm{pH}$ 8-9, a pale yellow solid will begin to precipitate, which is the desired product coming out of solution. Stir or swirl the aqueous solution when adding solid $\mathrm{K}_{2} \mathrm{CO}_{3}$ to avoid localized effervescence.

(xii) Remove the solid from the mixture by filtration using a sintered funnel. Wash the solid with $20 \mathrm{~mL}$ of $1 \mathrm{M}$ aqueous $\mathrm{K}_{2} \mathrm{CO}_{3}$ solution. Wash the solid with $10 \mathrm{~mL}$ of distilled $\mathrm{H}_{2} \mathrm{O}$, twice.

(xiii) Dry the solid, compound 13, under high vacuum for $24 \mathrm{~h}$. The expected yield for intermediate 13 is $50 \%(1.10 \mathrm{~g}$ over 3 steps, $n=5)$.

\section{? TROUBLESHOOTING}

(xiv) Characterize and check the purity of the compound by NMR $\left({ }^{1} \mathrm{H}\right.$ and $\left.{ }^{13} \mathrm{C}\right)$, mass spectrometry, and HPLC analysis. The $R_{\mathrm{f}}$ value of the product is 0.42 in $1: 9$ (vol/vol) $\mathrm{MeOH}: \mathrm{CH}_{2} \mathrm{Cl}_{2}$. Compound characterization can be found in the Supporting Data (S4).

PAUSE POINT Compound $\mathbf{1 3}$ can be stored at ambient temperature for six months.

\section{(B) Synthesis of compound 14 TIMING 4-6 $\mathrm{h}$}

(i) Add $0.97 \mathrm{~g}$ of compound $13(0.0057 \mathrm{~mol})$ and $10 \mathrm{~mL}$ glacial acetic acid to a $100 \mathrm{~mL}$ round-bottom flask equipped with a Teflon-coated magnetic stir bar. 
(ii) Dissolve $3.95 \mathrm{~g}$ of $\mathrm{NaNO}_{2}(0.057 \mathrm{~mol})$ in $5 \mathrm{~mL}$ of $\mathrm{H}_{2} \mathrm{O}$. Add this solution to the flask from step (i) drop-wise via a syringe and stir the reaction at ambient temperature for $4 \mathrm{~h}$.

CRITICAL STEP In our hands, conducting the reaction in an overall lower proportion of aqueous $\mathrm{AcOH}$ led to reduced yield of the desired product in our hands. We suggest a final reaction solution of approximately $66 \% \mathrm{vol} / \mathrm{vol}$ aqueous $\mathrm{AcOH}$ for the reaction, which in our hands resulted in a yield of $72 \%$.

(iii) Check the progress of the reaction by TLC analysis. The $R_{\mathrm{f}}$ value of the desired product 14 is 0.85 in a $1: 9$ (vol/vol) mixture of $\mathrm{MeOH}$ and $\mathrm{CH}_{2} \mathrm{Cl}_{2}$.

(iv) After completion of the reaction, transfer the reaction mixture into a $50 \mathrm{~mL}$ separating funnel and extract the product with $20 \mathrm{~mL}$ of $\mathrm{CH}_{2} \mathrm{Cl}_{2}$. Wash the organic layer with $20 \mathrm{~mL}$ of brine, followed by $20 \mathrm{~mL}$ of saturated aqueous $\mathrm{Na}_{2} \mathrm{SO}_{3}$ solution. Dry the organic layer over anhydrous $\mathrm{MgSO}_{4}(10 \mathrm{~g})$ to remove the residual water. Remove the $\mathrm{MgSO}_{4}$ by filtration, and concentrate the filtrate under reduced pressure on a rotary evaporator at $40^{\circ} \mathrm{C}$ for approximately $10 \mathrm{~min}$.

(v) Dissolve the residue from step (iv) in $3 \mathrm{~mL}$ of $\mathrm{CH}_{2} \mathrm{Cl}_{2}$, and adsorb onto Celite ${ }^{\circledR}$ under reduced pressure on a rotary evaporator at $40{ }^{\circ} \mathrm{C}$ for approximately $5 \mathrm{~min}$, or until dry.

(vi) Load the Celite ${ }^{\circledR}$ onto a silica gel (Geduran- Si 60) column (30 mm diameter), and elute the column with $\mathrm{CH}_{2} \mathrm{Cl}_{2}$ (typically 2-3 column volumes) under nitrogen pressure (flash chromatography), collecting fractions $(10 \mathrm{~mL})$.

(vii) Run TLC analysis of the fractions to identify compound 14, and combine the desired fractions. The $R_{\mathrm{f}}$ value of the desired product is 0.85 in a $1: 9$ (vol/vol) mixture of $\mathrm{MeOH}$ and $\mathrm{CH}_{2} \mathrm{Cl}_{2}$. Remove the $\mathrm{CH}_{2} \mathrm{Cl}_{2}$ under reduced pressure on a rotary evaporator at $40{ }^{\circ} \mathrm{C}$ for approximately 20 min, or until dry.

(viii) Dry the resulting solid, compound 14, under high vacuum for $1 \mathrm{~h}$.

(ix) The expected yield for compound 14 is $72 \%(0.83 \mathrm{~g}, n=3)$ as a pale yellow solid.

(x) Characterize and check the purity of the compound by NMR $\left({ }^{1} \mathrm{H}\right.$ and $\left.{ }^{13} \mathrm{C}\right)$, mass spectrometry, and HPLC analysis. Characterization can be found in the Supporting Data (S5).

PAUSE POINT Compound 14 can be stored at ambient temperature for 3 months.

Please note, that compound $\mathbf{1 4}$ can be considered to be the first useful product of this synthetic procedure, and could be attached to a biologically active compound via an ester coupling reaction. At this point in the procedure, we advise referring back to Figure 2, in order to proceed with the synthetic route applicable to the functional group required.

\section{(C) Synthesis of compound 15 TIMING 3-5 h}

(i) Add $0.23 \mathrm{~g}$ of compound $14(0.0012 \mathrm{~mol})$ to a $50 \mathrm{~mL}$ oven dried round-bottom flask equipped with a Teflon-coated magnetic stir bar and rubber septum. Flush the flask with argon by inserting a needle attached with a balloon filled with argon gas.

(ii) Dissolve the compound by adding $6 \mathrm{~mL}$ of anhydrous THF and $0.5 \mathrm{~mL}$ of $\mathrm{MeOH}$. Cool the solution to $0{ }^{\circ} \mathrm{C}$ using an ice bath.

(iii) Add to the reaction mixture at $0-^{\circ} \mathrm{C} 0.13 \mathrm{~g}$ of $\mathrm{NaBH}_{4}(0.0035 \mathrm{~mol})$ portion-wise and stir for $45 \mathrm{~min}$ and then at ambient temperature for $1 \mathrm{~h}$.

(iv) Cool the reaction mixture to $0{ }^{\circ} \mathrm{C}$ using an ice bath. Quench the reaction by adding ice (10 g) to the reaction mixture.

(v) Allow the reaction mixture to warm to ambient temperature, and adjust the $\mathrm{pH}$ of the solution to 7 , as determined by universal indicator paper, using $1 \mathrm{M}$ aqueous $\mathrm{HCl}$ solution. 
(vi) Saturate the aqueous solution with solid $\mathrm{NaCl}$, and transfer the resulting mixture to a $50 \mathrm{~mL}$ separating funnel.

CRITICAL STEP The aqueous layer must be saturated to drive the desired organic components into the organic solvent used in the next step.

(vii) Extract the organic components with EtOAc $(5 \times 15 \mathrm{~mL})$. Combine the organic layers, and transfer them to a $250 \mathrm{~mL}$ separating funnel and wash with $60 \mathrm{~mL}$ of a saturated aqueous $\mathrm{NaHCO}_{3}$ solution. Dry the organic layer over anhydrous $\mathrm{MgSO}_{4}(20 \mathrm{~g})$ to remove the residual water. Remove the $\mathrm{MgSO}_{4}$ by filtration, and concentrate the filtrate under reduced pressure on a rotary evaporator at $40{ }^{\circ} \mathrm{C}$ for approximately 20 min, or until dry.

(viii) Dissolve the residue from step (vii) in $3 \mathrm{~mL}$ of $\mathrm{CH}_{2} \mathrm{Cl}_{2}$ and adsorb onto Celite ${ }^{\circledR}$ under reduced pressure on a rotary evaporator at $40^{\circ} \mathrm{C}$ for approximately $5 \mathrm{~min}$, or until dry.

(ix) Load the Celite ${ }^{\circledR}$ onto a silica gel (Geduran Si 60) column (20 mm diameter), and elute the column with PE and EtOAc (gradient, 50-100\% (vol/vol) EtOAc, typically 6-7 column volumes) under nitrogen pressure (flash chromatography), collecting $5 \mathrm{~mL}$ fractions.

(x) Run TLC analysis of the fractions to identify 15, and combine the desired fractions. The $R_{\mathrm{f}}$ value of the product is 0.5 in $9: 1$ ( $\left(\mathrm{vol} / \mathrm{vol}\right.$ ) mixture of $\mathrm{CH}_{2} \mathrm{Cl}_{2}$ and $\mathrm{MeOH}$. Remove the EtOAc under reduced pressure on a rotary evaporator at $40{ }^{\circ} \mathrm{C}$ for approximately $20 \mathrm{~min}$, or until dry.

(xi) Dry further the resulting solid, compound 15, under high vacuum for $1 \mathrm{~h}$.

(xii) The expected yield for compound 15 is $66 \%(0.11 \mathrm{~g}, n=3)$ as a pale yellow solid.

(xiii) Characterize and check the purity of the compound by NMR $\left({ }^{1} \mathrm{H}\right.$ and $\left.{ }^{13} \mathrm{C}\right)$, mass spectrometry, and HPLC analysis. Characterization can be found in the Supporting Data (S6).

PAUSE POINT Compound 15 can be stored at ambient temperature for 12 months.

\section{(D) Synthesis of compound 16 TIMING 4-6 $\mathrm{h}$}

(i) Add $0.20 \mathrm{~g}$ of compound $15(0.0013 \mathrm{~mol})$ to an oven dried $50 \mathrm{~mL}$ round-bottom flask equipped with a Teflon-coated magnetic stir bar and rubber septum.

(ii) Flush the flask with argon by inserting a needle attached with a balloon filled with argon gas.

(iii) Dissolve the compound by adding $8 \mathrm{~mL}$ of $\mathrm{CH}_{2} \mathrm{Cl}_{2}$ to the flask. Add $0.3 \mathrm{~mL}$ of distilled pyridine ( $0.0036 \mathrm{~mol}, 2.9$ eq.) via a syringe and needle, and cool the reaction mixture to $0{ }^{\circ} \mathrm{C}$ using an ice bath.

(iv) Prepare a separate solution of thionyl chloride $\left(0.28 \mathrm{~mL}, 0.00393\right.$ eq.) in $\mathrm{CH}_{2} \mathrm{Cl}_{2}(2 \mathrm{~mL})$, and add it to the reaction solution, drop-wise at $0{ }^{\circ} \mathrm{C}$, via a syringe and needle. Stir the resulting solution at $0{ }^{\circ} \mathrm{C}$ for $1 \mathrm{~h}$, followed by a further $1 \mathrm{~h}$ at ambient temperature.

(v) Check the progress of the reaction by TLC analysis. The $R_{\mathrm{f}}$ value of the product is 0.4 in 1:1 (vol/vol) mixture of EtOAc and PE.

(vi) Quench the reaction by addition of ice $(5 \mathrm{~g})$ to it, followed by $5 \mathrm{~mL}$ of saturated aqueous $\mathrm{NaHCO}_{3}$ solution. Transfer the solution to a $100 \mathrm{~mL}$ separating funnel, and add $\mathrm{H}_{2} \mathrm{O}(10 \mathrm{~mL})$.

! CAUTION Addition of concentrated saturated aqueous $\mathrm{NaHCO}_{3}$ should be done slowly with vigorous stirring in an open flask, as effervescence can occur.

(vii) Extract the organic components with $\mathrm{CH}_{2} \mathrm{Cl}_{2}(2 \times 15 \mathrm{~mL})$. Combine the organic layers, and wash them with $30 \mathrm{~mL}$ of brine. Dry the organic layer over anhydrous $\mathrm{MgSO}_{4}(10 \mathrm{~g})$ to remove the residual water. Remove the $\mathrm{MgSO}_{4}$ by filtration, and concentrate the filtrate under reduced pressure on a rotary evaporator at $40{ }^{\circ} \mathrm{C}$ for approximately $10 \mathrm{~min}$, or until dry. 
(viii) Dissolve the residue from step (vii) in $1 \mathrm{~mL}$ of EtOAc and adsorb onto Celite ${ }^{\circledR}$ under reduced pressure on a rotary evaporator at $40^{\circ} \mathrm{C}$ for approximately $5 \mathrm{~min}$, or until dry.

(ix) Load the Celite ${ }^{\circledR}$ onto a silica gel (Geduran Si 60) column (20 mm diameter), and elute the column with PE and EtOAc (gradient, 50-100\% (vol/vol) EtOAc, (typically 7-8 column volumes) under nitrogen pressure (flash chromatography), collecting $5 \mathrm{~mL}$ fractions.

(x) Analyze the fractions by TLC to identify compound 16, and combine the desired fractions. The $R_{\mathrm{f}}$ value of the product is 0.4 in $1: 1$ ( $\mathrm{vol} / \mathrm{vol})$ mixture of EtOAc and PE. Remove the EtOAc under reduced pressure on a rotary evaporator at $40{ }^{\circ} \mathrm{C}$ for approximately $20 \mathrm{~min}$, or until dry.

(xi) Dry the resulting solid, compound 16, under high vacuum for $1 \mathrm{~h}$.

(xii) The expected yield for compound 16 is $66 \%(0.11 \mathrm{~g}, n=2)$ as a pale yellow solid.

(xiii) Characterize and check the purity of the compound by NMR $\left({ }^{1} \mathrm{H}\right.$ and $\left.{ }^{13} \mathrm{C}\right)$, mass spectrometry, and HPLC analysis. Characterization can be found in the Supporting Data (S7).

PAUSE POINT Compound 16 can be stored at $0{ }^{\circ} \mathrm{C}$ for 2 months.

\section{(E) Synthesis of compound 17 TIMING 2-3 h}

(i) Add $0.10 \mathrm{~g}$ of compound $14(0.0005 \mathrm{~mol})$ to a $10 \mathrm{~mL}$ round-bottom flask equipped with a Tefloncoated magnetic stir bar and rubber septum.

(ii) Add to the round-bottom flask $2 \mathrm{~mL}$ of aqueous $0.75 \mathrm{M} \mathrm{NaOH}$ solution and stir the resulting suspension at ambient temperature for $2 \mathrm{~h}$. After this time a homogeneous solution will form.

(iii) Adjust the $\mathrm{pH}$ of the reaction mixture to 1 , as determined by universal indicator paper, using concentrated aqueous $\mathrm{HCl}$ solution. Upon approaching $\mathrm{pH}$ 1, an off-white precipitate forms. Add $15 \mathrm{~mL}$ of EtOAc to the reaction mixture, and transfer it to a $100 \mathrm{~mL}$ separating funnel.

(iv) Extract the organic components with EtOAc $(4 \times 15 \mathrm{~mL})$. Combine the organic layers and dry them over anhydrous $\mathrm{MgSO}_{4}(20 \mathrm{~g})$ to remove the residual water. Remove the $\mathrm{MgSO}_{4}$ by filtration, and concentrate the filtrate under reduced pressure on a rotary evaporator at $40{ }^{\circ} \mathrm{C}$ for approximately $20 \mathrm{~min}$, or until dry.

(v) Dry further the resulting solid under high vacuum for $2 \mathrm{~h}$.

(vi) The expected yield for compound 17 is $95 \%(0.082 \mathrm{~g}, n=2)$ as an off-white solid.

(vii) Characterize and check the purity of the compound by NMR $\left({ }^{1} \mathrm{H}\right.$ and $\left.{ }^{13} \mathrm{C}\right)$, mass spectrometry, and HPLC analysis. Characterization can be found in the Supporting Data (S8).

PAUSE POINT Compound 17 can be stored at ambient temperature for 6 months.

\section{(F) Synthesis of compound 18 TIMING $3 \mathrm{~d}$}

(i) Add $0.05 \mathrm{~g}$ of compound $15(0.00031 \mathrm{~mol})$ and $0.16 \mathrm{~g}$ of $\mathrm{MnO}_{2}(0.0018 \mathrm{~mol})$ to a $10 \mathrm{~mL}$ roundbottom flask equipped with a Teflon-coated magnetic stir bar and rubber septum.

(ii) Flush the flask with argon by inserting a needle attached with a balloon filled with argon gas.

(iii) Dissolve the compound by adding to the round bottom flask $2.7 \mathrm{~mL}$ of $\mathrm{CH}_{2} \mathrm{Cl}_{2}$ and $0.7 \mathrm{~mL}$ of acetone via a syringe and needle. Stir the reaction mixture at ambient temperature for $3 \mathrm{~d}$.

(iv) Filter the reaction mixture through a bed of Celite ${ }^{\circledR}$ to remove the $\mathrm{MnO}_{2}$, and wash the Celite ${ }^{\circledR}$ with $\mathrm{CH}_{2} \mathrm{Cl}_{2}(10 \mathrm{~mL})$. Combine the filtrates, and concentrate them under reduced pressure on a rotary evaporator at $40^{\circ} \mathrm{C}$ for approximately $10 \mathrm{~min}$, or until dry.

(v) Dissolve the residue in $2 \mathrm{~mL}$ of acetone and adsorb onto Celite ${ }^{\circledR}$ under reduced pressure on a rotary evaporator at $40^{\circ} \mathrm{C}$ for approximately $5 \mathrm{~min}$, or until dry. 
(vi) Load the Celite ${ }^{\circledR}$ onto a silica gel (Geduran Si 60) column (10 mm diameter), and elute the column with $\mathrm{PE}$ and acetone (1:1 vol/vol, typically 4-5 column volumes) under nitrogen pressure (flash chromatography), collecting $5 \mathrm{~mL}$ fractions.

(vii) Analyze the fractions by TLC to identify compound 18, and combine the desired fractions. The $R_{\mathrm{f}}$ value of the product is 0.7 in 1:1 ( $\mathrm{vol} / \mathrm{vol})$ mixture of acetone and PE. Remove the volatile components under reduced pressure on a rotary evaporator at $40{ }^{\circ} \mathrm{C}$ for approximately $20 \mathrm{~min}$, or until dry.

(viii) Dry the resulting solid, compound 18, under high vacuum for $1 \mathrm{~h}$.

(ix) The expected yield for compound 18 is $52 \%(0.025 \mathrm{~g}, n=2)$ as a colourless solid.

(x) Characterize and check the purity of the compound by NMR $\left({ }^{1} \mathrm{H}\right.$ and $\left.{ }^{13} \mathrm{C}\right)$, mass spectrometry, and HPLC analysis. Characterization can be found in the Supporting Data (S9).

PAUSE POINT Compound 18 can be stored at $-20^{\circ} \mathrm{C}$ for 12 months.

Please note, the following protocol steps use the bioreductive compound $\mathrm{CH}-01$, previously developed in our laboratory as an example subject. Should the reader desire to use $\mathrm{CH}-01$ as a control compound, details concerning synthesis and analytical data for this molecule can be found in Cazares-Körner 2013 .

The products from Step 1| (B-F) can be used to functionalize a biologically active molecule, as previously described (Figure 4). Any prodrug resulting from this functionalization can be applied to the following procedure steps $2|-5|$.

2| Typical procedure for zinc reduction method: Reduction of compound 1 (CH-01) TIMING 16 h plus analysis.

(i) Add $1.0 \mathrm{mg}$ of subject compound $(0.0021 \mathrm{~mol}$ for $\mathrm{CH}-01$ (which is used here as a representative compound) to a $5 \mathrm{~mL}$ round-bottom flask equipped with a Teflon-coated magnetic stir bar and rubber septum.

(ii) Add $2 \mathrm{~mL}$ of DMF to the reaction flask.

(iii) Add $20 \mu \mathrm{L}$ of $10 \% \mathrm{wt} / \mathrm{vol}$ aqueous ammonium chloride to the reaction solution.

(iv) Take a $100 \mu \mathrm{L}$ of aliquot from the reaction solution. This will serve as $T=0$ for the HPLC analysis.

CRITICAL STEP The T=0 aliquot must be taken before the addition of zinc in the next step, as the reduction reaction will occur rapidly.

(v) Add $5 \mathrm{mg}$ of zinc dust $(0.0765 \mathrm{~mol}, 36$ eq. for $\mathrm{CH}-01)$ to the reaction mixture and stir at ambient temperature for $16 \mathrm{~h}$.

(vi) Collect aliquots of the reaction mixture at $T=1 \mathrm{~h}$ and $T=16 \mathrm{~h}$. Analyze aliquots by HPLC (see Equipment Setup and Table 1). Please note that the HPLC method outlined in Table 1 may require adjustment for other compounds. Please further note that we found reduction from nitro to the amine $\left(R_{1}=R_{2}=H\right.$ in Figure 1$)$ to be complete by $16 \mathrm{~h}$, as determined by HPLC analysis of the solution. Should monitoring of reduction be desired by this method, we recommend collecting $100 \mu \mathrm{L}$ aliquots at the desired time points $(0.5 \mathrm{~h}, 1 \mathrm{~h}, 2 \mathrm{~h}$, etc.).

? TROUBLESHOOTING

CRITICAL STEP Allow the reaction mixture to settle before collecting aliquots. Zinc particles may block flow in the HPLC system. Alternatively allow aliquots to settle and remove the supernatant from excess zinc 
metal. Filtered tips (Supelco, Iso-Disc ${ }^{\text {TM }}$ Filters, PTFE-4-4, size x porosity: $4 \mathrm{~mm}$ x $0.45 \mu \mathrm{m}$ ) when using a syringe helps to avoid this problem.

3| Typical procedure for zinc reduction method: determination of compound 1 (CH-01) fragmentation TIMING $24 \mathrm{~h}$ plus analysis.

(i) $\quad$ Add $95 \mu \mathrm{L}$ of $0.1 \mathrm{M} \mathrm{pH} 7.4 \mathrm{~K}_{2} \mathrm{HPO}_{4}$ buffer to a $2 \mathrm{~mL}$ microfuge tube.

(ii) Collect $5 \mu \mathrm{L}$ of the $\mathrm{T}=16 \mathrm{~h}$ aliquot collected in step 2| (vi) and add it to the buffer solution.

(iii) Incubate the resulting solution at $37^{\circ} \mathrm{C}$ for $24 \mathrm{~h}$.

(iv) Analyze the solution by HPLC (see Equipment setup and Table 1), and determine the ratio of the remaining prodrug, its reduced metabolite, and active inhibitor. Please note, the reduced prodrug of representative compound $\mathrm{CH}-01$ was found to be stable in DMF, the reaction solvent used in step 2| (vi). The reduced amine species $\left(R_{1}=R_{2}=H\right.$ in Figure 1) fragmented when incubated in buffer solution as in step 3|. Depending on the propensity of the reduced intermediate of your chosen prodrug to fragment, some fragmentation may already occur in step 2|. This can again be determined by HPLC analysis.

?TROUBLESHOOTING

4| Typical procedure for NADPH-CYP reductases assay: in vitro reduction of compound 1 (CH-01) TIMING 1-24 $\mathrm{h}$ plus analysis.

(i) Prepare a stock solution of compound 1 in DMSO such that the volume of DMSO added is less than $1 \%$ of the total assay volume.

CRITICAL STEP A typical DMSO stock concentration for use in the assay should be in the range of 0.25-10 mM.

(ii) Take two $5 \mathrm{~mL}$ vials, each equipped with a screw-on cap.

(iii) To each vial add:

- $50 \mu \mathrm{L}$ of Solution A

- $10 \mu \mathrm{L}$ of Solution B

- $\quad 729.3 \mu \mathrm{L}$ of deionized $\mathrm{H}_{2} \mathrm{O}$

- $200 \mu \mathrm{L}$ of $0.5 \mathrm{M} \mathrm{pH} 7.4 \mathrm{KHPO}_{4}$ buffer

- $1 \mu \mathrm{L}$ of DMSO stock solution

CRITICAL STEP Solutions A and B represent an NADPH regeneration system, supplied by Corning.

CRITICAL STEP The final concentration of the substrate prodrug may be adjusted. We recommend HPLC analysis of the compound's UV absorbance at various concentrations. The final compound concentration in the assay may then be adjusted, such that the compound may be visualized in the assay aliquots by HPLC. For $\mathrm{CH}-01$, our representative compound, the DMSO stock solution used was $10 \mathrm{mM}$, and the final $\mathrm{CH}-01$ concentration in the reaction mixture was $10 \mu \mathrm{M}$.

(iv) Cool each vial containing the assay solution to $0-4{ }^{\circ} \mathrm{C}$ with ice.

(v) Add $9.7 \mu \mathrm{L}$ of bactosomal human NADPH-CYP reductases (enzyme concentration in the purchased solution: $10.3 \mathrm{nmol} / \mathrm{mL}$ ) to each vial. The final enzyme concentration in the reaction solution is $92 \mathrm{pmol} / \mathrm{mL}$

CRITICAL STEP Enzyme concentration between batches may vary. We recommend maintaining a final enzyme concentration of $92 \mathrm{pmol} / \mathrm{mL}$. Volume adjustments to change the enzyme concentration should be compensated for by modifying the volume of deionized $\mathrm{H}_{2} \mathrm{O}$ appropriately. 
CRITICAL Bactosomal human NADPH-CYP reductase enzymes should be kept at $-80^{\circ} \mathrm{C}$, and thawed on ice thoroughly before use, to avoid denaturing of the enzyme.

(vi) Label one vial "Hypoxia" and the other "Normoxia".

(vii) Take two $200 \mu \mathrm{L}$ microfuge tubes, and to each add $50 \mu \mathrm{L}$ of $\mathrm{MeCN}$.

(viii) Take a $50 \mu \mathrm{L}$ aliquot from vial "Hypoxia". Add it to the $50 \mu \mathrm{L}$ of $\mathrm{MeCN}$ in one of the microfuge tubes. Label this microfuge tube "Hypoxia, $\mathrm{T}=0$ ". Store at $-20^{\circ} \mathrm{C}$.

PAUSE POINT. Aliquots may be stored at $-20^{\circ} \mathrm{C}$ for up to two weeks awaiting HPLC analysis.

(ix) Repeat the procedure outlined in step (viii) for vial "Normoxia".

(x) Place vial "Hypoxia" inside a Bactron ${ }^{\circledR}$ II anaerobic chamber (Shell Labs) at $<0.1 \% \mathrm{O}_{2}$ set to incubate at $37{ }^{\circ} \mathrm{C}$. Place vial "Normoxia" inside an incubation chamber at $37.0{ }^{\circ} \mathrm{C}$ under aerobic $\left(21 \% \mathrm{O}_{2}\right)$ conditions.

(xi) Repeat the procedure outlined in steps (vii)-(xi) for T=2 h, $4 \mathrm{~h}, 24 \mathrm{~h}$, or for other desired time points. CRITICAL STEP Do not remove the vials from their respective incubation chambers. The $1 \mathrm{~mL}$ assay volume will take time to equilibrate with anaerobic conditions (approximately 20-30 min). Place the screw-on caps on top of each vial to minimize evaporation. Do not seal them, as this will limit exposure to the chamber's atmosphere.

CRITICAL STEP The suggested time points are those of an example assay, here used to determine bioreduction of compound 1 . Where reduced concentrations of substrate prodrug are used, time points may be shortened.

(xii) Remove aliquot samples from $-20^{\circ} \mathrm{C}$ freezer and defrost them at ambient temperature.

(xiii) Centrifuge the thawed samples at $13,000 \mathrm{~g}$ for $10 \mathrm{~min}$ at $4{ }^{\circ} \mathrm{C}$. Remove the supernatant from each sample.

(xiv) Analyze each sample (both "Hypoxia" and "Normoxia" at T = 0, 2, 4, 24 h) by HPLC (see Equipment setup and Table 1).

\section{? TROUBLESHOOTING}

(xv) Determine the ratio of the remaining prodrug, its reduced metabolite and active inhibitor for each sample.

\section{5| Typical procedure for in vitro evaluation of the bioreductive prodrug TIMING 3-5 d}

Use of this assay is a quick, efficient, representative method for indicating whether a cell line of interest is capable of $\mathrm{O}_{2}$-dependent reduction of a bioreductive candidate compound. This protocol employs, but is not limited to, RKO (colorectal) cells as a representative cell line for use in bioreductive experiments. We have found that HCT116, OE21, A549, HepG2 and H1299 cells are also suitable for these experiments. Purchase and culture details can be found at Igcstandards-atcc.org.

(i) Culture RKO (colorectal) cells in a cell-culture flask, for example a $75 \mathrm{~cm}^{3}$ Corning $^{\circledR}$ flask, in the appropriate media (Dulbecco's Modified Eagle Medium (DMEM) containing 10\% vol/vol fetal bovine serum (FBS), $100 \mathrm{U} / \mathrm{mL}$ of penicillin (P) and $100 \mu \mathrm{g} / \mathrm{mL}$ of streptomycin (S/M)). Culture the cells in a standard humidified incubator at $37{ }^{\circ} \mathrm{C}$ and $5 \% \mathrm{CO}_{2}$ until approximately $70 \%$ confluence. Please note cells should be growing exponentially.

! CAUTION Regularly check that the cell lines used in your research match their recognized cell line identity criteria and are not infected with mycoplasma. 
(ii) Seed 250,000 cells into a $6 \mathrm{~cm}$ glass dish. Four dishes will be required.

CRITICAL STEP Glass dishes are required to ensure that oxygen levels decrease as rapidly as possible. Plastic dishes, which retain oxygen, can also be used but longer incubation times may be needed.

(iii) Incubate the dishes in a standard humidified incubator at $37^{\circ} \mathrm{C}$ and $5 \% \mathrm{CO}_{2}$ for $15 \mathrm{~h}$.

(iv) Treat two of the dishes with a $25 \mu \mathrm{M}$ solution of the compound of interest in $5 \mathrm{~mL}$ fresh DMEM (10\% (vol/vol) FBS, $100 \mathrm{U} / \mathrm{mL}$ penicillin and $100 \mu \mathrm{g} / \mathrm{mL}$ streptomycin. The two other dishes should be used as negative controls (no bioreductive prodrug present) for hypoxic and normoxic conditions.

CRITICAL STEP Note that this is a representative concentration used for experiments with compound 1. Optimization of dose might be required to avoid issues associated with non-specific cytotoxicity.

(v) Incubate one dish dosed with the compound of interest, and one negative control dish in a BactronII anaerobic chamber (Shell Labs) for $6 \mathrm{~h}$ at $37^{\circ} \mathrm{C}$ and $<0.1 \% \mathrm{O}_{2}$. Incubate one dish dosed with compound of interest, and one negative control dish in a standard humidified incubator at $37{ }^{\circ} \mathrm{C}$ and $5 \% \mathrm{CO}_{2}$ for $6 \mathrm{~h}$.

(vi) Remove the medium from each dish, and wash the cells twice with $3 \mathrm{~mL}$ of PBS.

(vii) Add $1 \mathrm{~mL}$ of PBS to each dish, and using a cell scraper, gently detach the cells from the glass surface. Transfer each $1 \mathrm{~mL}$ cell suspension to a $2.5 \mathrm{~mL}$ microfuge tube.

CRITICAL STEP Scrape cells gently to avoid damaging them in the process. Damage to cells will lead to potential loss of endogenous metabolites and decrease overall cell number for analysis.

(xiii) Centrifuge the cell suspensions at a speed of $250-350 \mathrm{~g}$ for $10 \mathrm{~min}$ at $4{ }^{\circ} \mathrm{C}$. Remove and discard the supernatant to leave the cell pellet.

(ix) Lyse the cells with $100 \mu \mathrm{L}$ of $\mathrm{MeCN}$ or $3 \%$ (vol/vol) trichloroacetic acid (TCA) in PBS. Centrifuge the cells at $13,000 \mathrm{~g}$ for $15 \mathrm{~min}$ at $4{ }^{\circ} \mathrm{C}$. Remove and keep the supernatant.

(x) Analyze the supernatant by HPLC (see Equipment setup and Table 1) to determine the intracellular presence of metabolites of the compound of interest.

? TROUBLESHOOTING 
Troubleshooting advice can be found in Table 2 .

TABLE 2. Troubleshooting table.

\begin{tabular}{|c|c|c|c|}
\hline Step & Problem & Possible reason & Solution \\
\hline 1| (A) (iii) & $\begin{array}{l}\text { The yellow suspension } \\
\text { doesn't formed. }\end{array}$ & $\mathrm{NaH}$ is inactive. & Purchase fresh $\mathrm{NaH}$. \\
\hline 1| (A) (xiii) & $\begin{array}{l}\text { Low yield of the } \\
\text { product. }\end{array}$ & $\begin{array}{l}\text { EtOH remains in reaction } \\
\text { solution after rotary } \\
\text { evaporation. }\end{array}$ & $\begin{array}{l}\text { Ensure that all EtOH is removed } \\
\text { through rotary evaporation and the } \\
\text { reaction mixture is adequately } \\
\text { concentrated. }\end{array}$ \\
\hline \multirow[t]{2}{*}{ 2| (vi) } & $\begin{array}{l}\text { Prodrug is not } \\
\text { visualized by HPLC. }\end{array}$ & $\begin{array}{l}\text { Visualization at } \\
\text { inappropriate wavelength. }\end{array}$ & $\begin{array}{l}\text { Look for a maximum in the UV trace } \\
\text { and collect data at this wavelength. }\end{array}$ \\
\hline & $\begin{array}{l}\text { Zinc reduction yields } \\
\text { multiple peaks by } \\
\text { HPLC analysis. }\end{array}$ & $\begin{array}{l}\text { Compound functionalities } \\
\text { other than the nitro group } \\
\text { sensitive to zinc } \\
\text { reduction. }\end{array}$ & $\begin{array}{l}\text { Proceed to evaluate compound in } \\
\text { NADPH-CYP reductases assay. }\end{array}$ \\
\hline \multirow[t]{2}{*}{$3 \mid$ (iv) } & $\begin{array}{l}\text { The prodrug fragments } \\
\text { prior to buffer } \\
\text { treatment. }\end{array}$ & $\begin{array}{l}\text { Propensity for } \\
\text { fragmentation upon } \\
\text { reduction is good. }\end{array}$ & $\begin{array}{l}\text { Proceed to evaluate compound in } \\
\text { NADPH-CYP reductases assay. }\end{array}$ \\
\hline & $\begin{array}{l}\text { Bioreductive group } \\
\text { (nitro) gets reduced } \\
\text { but does not fragment. }\end{array}$ & $\begin{array}{l}\text { Reduced metabolites } \\
\text { (amino or nitroso) are } \\
\text { stable and have poor } \\
\text { fragmentation propensity. }\end{array}$ & $\begin{array}{l}\text { Allow longer incubation in potassium } \\
\text { phosphate buffer. If the problem } \\
\text { persists, use a different bioreductive } \\
\text { group or use a linker (like carbamate } \\
\text { or carbonate) to improve } \\
\text { fragmentation. }\end{array}$ \\
\hline \multirow[t]{4}{*}{ 4| (xiv) } & $\begin{array}{l}\text { Cannot visualize the } \\
\text { parent compound or } \\
\text { it's metabolites by } \\
\text { HPLC. }\end{array}$ & $\begin{array}{l}\text { Compound concentration } \\
\text { is too low. }\end{array}$ & $\begin{array}{l}\text { Increase concentration of the } \\
\text { compound in the assay. Please note } \\
\text { this approach requires either } \\
\text { increased an increased } \\
\text { duration/number of time points or a } \\
\text { corresponding increase in enzyme } \\
\text { concentration from the recommended } \\
92 \mathrm{pmol} / \mathrm{mL}\end{array}$ \\
\hline & $\begin{array}{l}\text { No metabolites } \\
\text { detected by HPLC. }\end{array}$ & $\begin{array}{l}\text { The enzyme has been } \\
\text { denatured. }\end{array}$ & $\begin{array}{l}\text { Ensure enzyme is stored in aliquots } \\
\text { at }-80^{\circ} \mathrm{C} \text {. Avoid freeze-thawing the } \\
\text { whole batch between experiments. }\end{array}$ \\
\hline & & $\begin{array}{l}\text { The prodrug is not a } \\
\text { substrate for the enzyme. }\end{array}$ & $\begin{array}{l}\text { Consider employing alternative } \\
\text { bioreductive groups. }\end{array}$ \\
\hline & & $\begin{array}{l}\text { The concentration of the } \\
\text { parent compound is too } \\
\text { high. }\end{array}$ & $\begin{array}{l}\text { Reduce concentration of parent } \\
\text { compound. }\end{array}$ \\
\hline \multirow[t]{4}{*}{$5 \mid(x)$} & $\begin{array}{l}\text { No metabolites } \\
\text { detected by HPLC. }\end{array}$ & $\begin{array}{l}\text { The chosen cell line lacks } \\
\text { appropriate reductase } \\
\text { enzymes. }\end{array}$ & $\begin{array}{l}\text { Choose an alternative cell line, or } \\
\text { determine the presence of reductase } \\
\text { of interest by western blot analysis. }\end{array}$ \\
\hline & $\begin{array}{l}\text { Neither parent } \\
\text { compound nor } \\
\text { metabolites detected } \\
\text { by HPLC. }\end{array}$ & $\begin{array}{l}\text { Concentration of the } \\
\text { compound is too low or } \\
\text { too few cells are used in } \\
\text { the assay. }\end{array}$ & $\begin{array}{l}\text { Repeat the assay with an increased } \\
\text { dose of compound of interest, or with } \\
\text { a greater number of cells. }\end{array}$ \\
\hline & & $\begin{array}{l}\text { The compound is } \\
\text { metabolically unstable }\end{array}$ & $\begin{array}{l}\text { Select an alternative cell line with } \\
\text { reduced metabolic activity. }\end{array}$ \\
\hline & $\begin{array}{l}\text { The reduced } \\
\text { compound is detected } \\
\text { by HPLC, but not the } \\
\text { fragmentation product. }\end{array}$ & $\begin{array}{l}\text { Propensity for in vitro } \\
\text { fragmentation of the } \\
\text { reduced metabolite is } \\
\text { poor. }\end{array}$ & $\begin{array}{l}\text { Consider the use of bioreductive } \\
\text { linker groups, such as carbamates, to } \\
\text { enhance leaving group ability. }\end{array}$ \\
\hline
\end{tabular}




\section{ANTICIPATED RESULTS}

Step 1| Supporting information provides characterization data for compounds 13-18.

Step 2| Analysis of aliquots by HPLC should reveal reduction of the nitro functionality to hydroxylamine, nitroso intermediates or amino product. Identity of the metabolites observed can be confirmed via LCMS analysis.

Step 3| Incubation in buffer should induce fragmentation of the reduced prodrug species.

Step 4| Aliquot evaluation by HPLC of the hypoxia-activated prodrug incubated with bactosomal human NADPH-CYP reductases under hypoxic conditions should reveal an increase in the concentration of fragmentation product with time. Under normoxic conditions, the prodrug should remain stable.

Step 5| Hypoxia-activated prodrug should not show activation under normoxic conditions. Under hypoxic conditions, the reduction step occurs and the fragmentation product is detectable.

\section{TIMING}

Step 1:

(A) Compound 13 8-10 h

(B) Compound 14 4-6 h

(C) Compound 15 3-5 h

(D) Compound 16 4-6 h

(E) Compound 17 2-3 h

(F) Compound $183 \mathrm{~d}$

Step 2: $16 \mathrm{~h}$ plus analysis

Step 3: $24 \mathrm{~h}$ plus analysis

Step 4: 1-24 h plus analysis

Step 5:3-5 d

\section{ACKNOWLEDGEMENTS}

SJC, EMH and LJOC thank MRC for the award of a studentship to LJOC. SJC, EMH and CC-K thank Cancer Research UK for the award of a studentship to CC-K. SJC, EMH and CNGE thank Cancer Research UK and EPSRC for the award of a studentship to CNGE, through the CR-UK and EPSRC Cancer Imaging Centre in Oxford (OCIC). SJC and JS thank the European Commission for the award of a Marie Curie Fellowship to JS (PIIF-GA-2012-331327, HYPOXPROBE). EMH thanks Cancer Research UK for research funding. SJC thanks St Hugh's College, Oxford, for research funding.

\section{AUTHOR CONTRIBUTIONS}

The study was conceived and planned by SJC and EMH. The chemical synthesis was conducted by LJOC, CC-K, JS and CNGE. The chemical synthesis was supervised by SJC. The in vitro bioreduction studies were performed by LJOC, CC-K and MRLS. The in vitro bioreduction studies were supervised by SJC and EMH. The cellular bioreduction studies were performed by LJOC, CC-K and MRLS. The cellular bioreduction studies were supervised by EMH. All authors interpreted the data. The manuscript was written by LJOC, JS, $\mathrm{EMH}$ and SJC. All authors commented on the manuscript.

\section{COMPETING FINANCIAL INTERESTS}

The authors declare no competing financial interests.

Reprints and permissions information is available online at http: //www.nature.com/reprints/index.html. 


\section{References}

1. Hammond, E. M. et al. The meaning, measurement and modification of hypoxia in the laboratory and the clinic. Clin. Oncol. (R. Coll. Radiol.) 26, 277-288 (2014).

2. McKeown, S. R. Defining normoxia, physoxia and hypoxia in tumours-implications for treatment response. Br. J. Radiol. 87, 20130676 (2014).

3. Wilson, W. R. \& Hay, M. P. Targeting hypoxia in cancer therapy. Nat. Rev. Cancer 11, 393-410 (2011).

4. Thomlinson, R. H. \& Gray, L. H. The Histological Structure of Some Human Lung Cancers and the Possible Implications for Radiotherapy. Br. J. Cancer 9, 539-549 (1955).

5. Vaupel, P. The role of hypoxia-induced factors in tumor progression. Oncologist 9, 10-17 (2004).

6. Yasui, H. et al. Low-Field Magnetic Resonance Imaging to Visualize Chronic and Cycling Hypoxia in Tumor-Bearing Mice. 70, 6427-6436 (2010).

7. Nordsmark, M. et al. Prognostic value of tumor oxygenation in 397 head and neck tumors after primary radiation therapy. An international multi-center study. Radiother. Oncol. 77, 18-24 (2005).

8. Begg, A. C., Stewart, F. A. \& Vens, C. Strategies to improve radiotherapy with targeted drugs. Nat. Rev. Cancer 11, 239-253 (2011).

9. Cazares-Korner, C. et al. $\mathrm{CH}-01$ is a Hypoxia-Activated Prodrug That Sensitizes Cells to Hypoxia/Reoxygenation Through Inhibition of Chk1 and Aurora A. ACS Chem. Biol. 8, 1451-1459 (2013).

10. O'Connor, L. J. et al. Efficient synthesis of 2-nitroimidazole derivatives and the bioreductive clinical candidate Evofosfamide (TH-302). Org. Chem. Front. 2, 1026-1029 (2015).

11. Cavalleri, B., Ballotta, R. \& Lancini, G. Synthesis of 1-alkyl-2-nitroimidazole-5-carboxaldehydes. J. Heterocycl. Chem. 9, 979-984 (1972).

12. Matteucci, M., Duan, J.-X., Jiao, H., Kaizerman, J., Ammons, S. and Hopkins, M. H. Phosphoramidate alkylator prodrugs. US Patent Office, WO 2007/002931 A2, 2007

13. Parveen, I., Naughton, D. P., Whish, W. \& Threadgill, M. D. 2-Nitroimidazol-5-ylmethyl as a potential bioreductively activated prodrug system: Reductively triggered release of the PARP inhibitor 5bromoisoquinolinone. Bioorg. Med. Chem. Lett. 9, 2031-2036 (1999).

14. Damen, E. W. P., Nevalainen, T. J., van den Bergh, T. J. M., de Groot, F. M. H. \& Scheeren, H. W. Synthesis of novel paclitaxel prodrugs designed for bioreductive activation in hypoxic tumour tissue. Bioorg. Med. Chem. 10, 71-77 (2002).

15. Ferrer, S., Naughton, D. P. \& Threadgill, M. D. H-1 NMR studies on the reductively triggered release of heterocyclic and steroid drugs from 4,7-dioxoindole-3-methyl prodrugs. Tetrahedron 59, 34453454 (2003).

16. Zhang, Z., Tanabe, K., Hatta, H. \& Nishimoto, S.-I. Bioreduction activated prodrugs of camptothecin: molecular design, synthesis, activation mechanism and hypoxia selective cytotoxicity. Org. Biomol. Chem. 3, 1905-1910 (2005).

17. Hay, M. P., Wilson, W. R. \& Denny, W. A. Nitroarylmethylcarbamate prodrugs of doxorubicin for use with nitroreductase gene-directed enzyme prodrug therapy. Bioorg. Med. Chem. 13, 4043-4055 (2005).

18. Thomson, P. et al. Hypoxia-driven elimination of thiopurines from their nitrobenzyl prodrugs. Bioorg. Med. Chem. Lett. 17, 4320-4322 (2007).

19. Granchi, C. et al. Bioreductively activated lysyl oxidase inhibitors against hypoxic tumours. ChemMedChem 4, 1590-1594 (2009).

20. Zhu, R. et al. 4-nitrobenzyloxycarbonyl derivatives of $\mathrm{O}(6)$-benzylguanine as hypoxia-activated prodrug inhibitors of $\mathrm{O}(6)$-alkylguanine-DNA alkyltransferase (AGT), which produces resistance to agents targeting the O-6 position of DNA guanine. J. Med. Chem. 54, 7720-7728 (2011).

21. Lindquist, K. E. et al. Selective radiosensitization of hypoxic cells using BCCA621C: a novel hypoxia activated prodrug targeting DNA-dependent protein kinase. Tumor Microenvironment and Therapy 46-55 (2013). doi:10.2478/tumor-2013-0003

22. Couch, G. D., Burke, P. J., Knox, R. J. \& Moody, C. J. Synthesis of 2-aryl-6-methyl-5-nitroquinoline derivatives as potential prodrug systems for reductive activation. Tetrahedron 64, 2816-2823 (2008).

23. Cui, L. et al. A new prodrug-derived ratiometric fluorescent probe for hypoxia: high selectivity of nitroreductase and imaging in tumor cell. Org. Lett. 13, 928-931 (2011).

24. Blanche, E. A., Maskell, L., Colucci, M. A., Whatmore, J. L. \& Moody, C. J. Synthesis of potential prodrug systems for reductive activation. Prodrugs for anti-angiogenic isoflavones and VEGF receptor tyrosine kinase inhibitory oxindoles. Tetrahedron 65, 4894-4903 (2009).

25. Naughton, D. P. Drug targeting to hypoxic tissue using self-inactivating bioreductive delivery systems. Adv. Drug Deliv. Rev. 53, 229-233 (2001).

26. Wardman, P. Some Reactions and Properties of Nitro Radical-Anions Important in Biology and Medicine. Environ. Health Perspect. 64, 309-320 (1985).

27. Foloppe, N. et al. Structure-based design of novel Chk1 inhibitors: insights into hydrogen bonding and protein-ligand affinity. J. Med. Chem. 48, 4332-4345 (2005). 
28. Larock, R. C. Comprehensive Organic Transformations. (Wiley-VCH, 1999). 